Article

\title{
Theoretical Investigation of the Hydrolytic Mechanism of $\alpha$-Functionalized Alkoxysilanes as Effective Crosslinkers and the Difficulty of Deep Vulcanization in RTV Silicone Rubber
}

\author{
Huihui Xu, Yanhong Gao, Zihou Liu and Yiling Bei * \\ Key Laboratory of Special Functional Aggregated Materials, Ministry of Education, \\ School of Chemistry and Chemical Engineering, Shandong University, Jinan 250100, China; \\ 201411546@mail.sdu.edu.cn (H.X.); A2936755368@163.com (Y.G.); EBLX22@163.com (Z.L.) \\ * Correspondence: beiyiling@sdu.edu.cn
}

Received: 21 July 2018; Accepted: 22 August 2018; Published: 24 August 2018

\begin{abstract}
The reactions between $\alpha-, \gamma$-ethylenediaminemethyl trimethyl-ketoxime silane ( $\alpha$-, $\gamma$-EAMOS) and $\mathrm{H}_{2} \mathrm{O}$ were investigated on the geometries of stationary points, the reaction pathway (IRC), thermodynamic and kinetic analysis by density functional theory (DFT) at the B3LYP/6-311G $(\mathrm{d}, \mathrm{p})$ level. Interestingly, the results showed that the hydrolysis activity of $\alpha$-EAMOS is higher than that of $\gamma$-EAMOS, due to the influence of an amino substituent in position $\alpha$-C on silicon. $\alpha$-EAMOS can be used as a superior crosslinker for room temperature vulcanized (RTV) silicone rubber to achieve rapid crosslinking without a toxic catalyst. Besides, compared with the reaction between $\alpha$-EAMOS and $\mathrm{H}_{2} \mathrm{O}$, the reactivity between $\alpha$-EAMOS and hydroxy siloxane $\left(\mathrm{HO}-\mathrm{Si}\left(\mathrm{CH}_{3}\right)_{2}-\mathrm{OSiH}_{3}\right)$ was discussed. Particularly, it revealed that the deep vulcanization of RTV silicone rubber is difficult.
\end{abstract}

Keywords: $\alpha$-, $\gamma$-ethylenediaminemethyl trimethyl-ketoxime silane; hydrolytic activity; ab initio calculation; density functional theory; RTV silicone rubber

\section{Introduction}

Carbofunctionalized trialkoxysilanes $\left(\mathrm{X}-\left(\mathrm{CH}_{2}\right)_{n}-\mathrm{Si}(\mathrm{OR})_{3}\right.$, where $\mathrm{X}$ is functional amines, chlorine, carboxyl etc., $n=1,2,3$ is called $\alpha-, \beta-, \gamma$-functionalized alkoxysilane, respectively) play a great role in organosilicon chemistry. They are widely used as coupling agents to connect inorganic and organic materials possessing various structures and properties [1,2]. And they are also used as crosslinkers for room temperature vulcanized (RTV) silicone rubber. The OR groups of trialkoxysilanes react with $\mathrm{H}_{2} \mathrm{O}$ to form silanols, which then condense with the polydimethylsiloxane (PDMS) to produce an elastomer with three-dimensional network structure [3,4]. The corresponding RTV silicone rubbers with excellent properties are widely used in sealants, adhesives, coatings, and spray foams [5-7].

Commercial crosslinkers used on a large scale have often been $\gamma$-functionalized alkoxysilanes $(n=3)$ because they are considered more stable than $\alpha$ - or $\beta$-functionalized alkoxysilanes ( $n=1$ or 2 , $\beta$-effect makes $\beta$-functionalized alkoxysilanes unstable) [8,9]. However, the influence of the functional group on $\mathrm{Si}-\mathrm{OR}$ of $\gamma$-functionalized alkoxysilanes is much smaller than that of $\alpha$-functionalized alkoxysilanes because the $\gamma$-group lies far away from Si. When it comes to crosslinkers for silicone rubber, it is usually necessary to add a toxic catalyst, such as organotin, to complete the rapid vulcanization at room temperature.

Now, some $\alpha$-silane-terminated prepolymers crosslink faster than the corresponding prepolymers produced from conventional $\gamma$-functionalized alkoxysilanes [10]. So, $\alpha$-functionalized alkoxysilanes get more attention in silicon chemistry. For example, chloromethyltriethoxysilane was used as a 
self-catalytic crosslinker in water-based silicone rubber, which then had low modulus and high elongation [11]. The use of $\alpha$-amine alkoxysilanes bearing piperazidine improved the stability of silicone rubber [12]. Meanwhile, various $\alpha$-amine functionalized alkoxysilanes as crosslinkers accelerated the curing rate of the silicone rubber [13]. Just now, a series of $\alpha$-amine ketoximesilanes [14] were prepared to be used as auto-catalyzed crosslinkers in RTV silicone rubber [15]. Thereby, it was simply proved by using density functional theory (DFT) calculations that $\alpha$-amine ketoximesilanes have fast hydrolysis rates [16].

Although there are many studies on $\alpha$-functionalized alkoxysilanes, the effect of the $\alpha$-functional amino group is not fully understood yet. The geometries of $\alpha-, \gamma$-functionalized silanes and their reaction processes with $\mathrm{H}_{2} \mathrm{O}$ need further investigation to find the hydrolytic mechanism, which is related to the vulcanization of RTV silicone rubber. Besides, as for the deep vulcanization of RTV silicone rubber, it is that the crosslinker first transforms to silanol ( $\mathrm{Si}-\mathrm{OH})$. When there is rare water involved, the reactions between the crosslinker and $\mathrm{H}_{2} \mathrm{O}$ and between the crosslinker and HO-PDMS are competitive. Particularly, the deep vulcanizing process of RTV silicone rubber is difficult [17-19]. But, there are rare studies accounting for this.

In this regard, we studied the reactions between $\alpha$-, $\gamma$-ethylenediaminemethyl trimethyl-ketoxime silane (EAMOS) and $\mathrm{H}_{2} \mathrm{O}$, respectively. They were simulated by DFT calculations for the geometries of stationary points, and thermodynamic and kinetic analysis. To reveal the difficulty of deep vulcanization of RTV silicone rubber, the reaction between $\alpha$-EAMOS and $\mathrm{H}_{2} \mathrm{O}$ and the reaction between $\alpha$-EAMOS and $\mathrm{HO}-\mathrm{Si}\left(\mathrm{CH}_{3}\right)_{2}-\mathrm{OSiH}_{3}$ were compared.

\section{Computational Methods}

Here, the computational methods referred to the default convergence limit of B3LYP/6-311G (d, p) of DFT in Gaussian 03 (C. 02, Jinan, China) [20]. DFT calculations were carried out using Becke's three-parameter hybrid function (B3LYP) level using the 6-311G $(\mathrm{d}, \mathrm{p})$ basis set. The geometry optimization was applied for the ground states and these ground states were assumed to be a singlet state. The theoretical calculations were performed by this quantum set. All the above-mentioned calculations for geometry optimization were carried out with the Gaussian 03 quantum chemistry program-package.

The reactions between $\alpha-, \gamma$-EAMOS and $\mathrm{H}_{2} \mathrm{O}$ were studied by using DFT at the B3LYP/6-311G $(\mathrm{d}, \mathrm{p})$ level. The molecules were optimized. The geometries of various stationary points and harmonic vibrational frequencies were calculated. Only one imaginary frequency for each transition state could be found. The reaction pathways were investigated and confirmed by intrinsic reaction coordinate (IRC) calculations (Figure 1). The changes of thermodynamic functions including entropy, enthalpy, free energies, and equilibrium constant were calculated through reactants, transition states, and products in Eyring transition state theory. Zero-point energy correction was also carried out at the B3LYP / 6-311G (d, p) level.

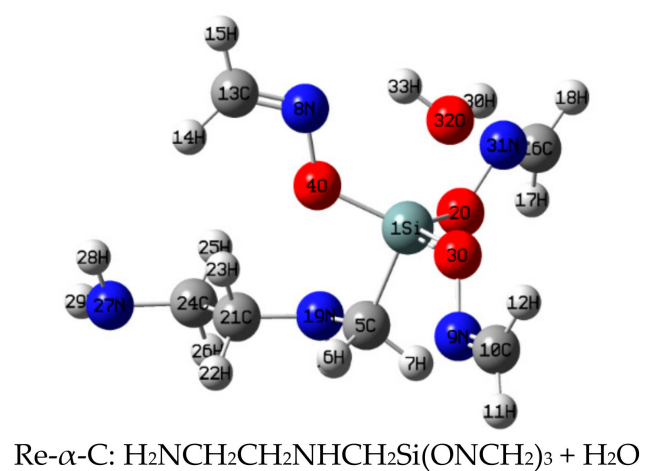

Figure 1. Cont. 


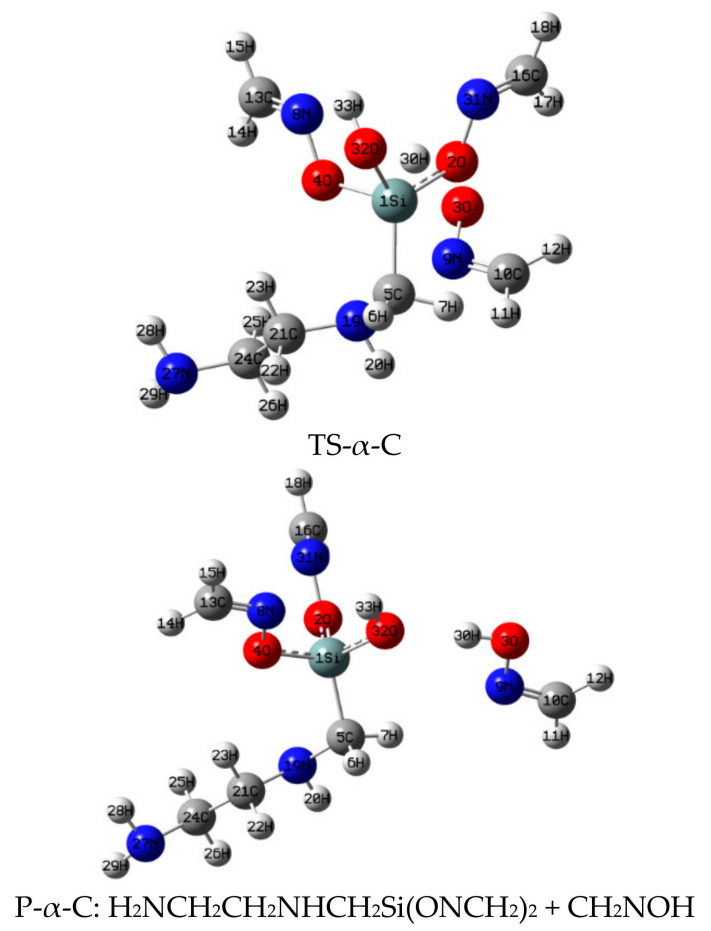

Figure 1. Geometries of stationary points of the reaction between $\alpha$-ethylenediaminemethyl trimethyl-ketoxime silane (EAMOS) and $\mathrm{H}_{2} \mathrm{O}$ at $\mathrm{B} 3 \mathrm{LYP} / 6-311 \mathrm{G}^{* *}$ level.

Having tried different reaction modes, the reaction path here needs the lowest energy. In order to guarantee the reality of the reaction path, the structures of transition states (the imaginary frequency is 1) were confirmed by vibration analysis. IRC of all the structures of transition states were calculated (Figure S1). The optimization was further performed along both sides of the IRC curve. One is reactants, and the other is products, which proved that the reaction path was reliable.

\section{Results and Discussion}

\subsection{Stationary Points and Pathways with $\alpha-E A M O S$ and $\mathrm{H}_{2} \mathrm{O}$ as an Example}

IRC calculation (Figure 1, Tables S1-S3) showed that in the reaction between $\alpha$-EAMOS and $\mathrm{H}_{2} \mathrm{O}$, the first step is the strong electronegative ${ }^{32} \mathrm{O}$ (NBO charge: -0.918) of $\mathrm{H}_{2} \mathrm{O}$, coordinated with two hydrogens $\left({ }^{30} \mathrm{H},{ }^{33} \mathrm{H}\right)$, moving to the electropositive ${ }^{1} \mathrm{Si}$ (distance of ${ }^{1} \mathrm{Si}^{32} \mathrm{O}$ decreased from $2.038 \AA$ to $1.803 \AA$, NBO charge: 2.156 ). Then, ${ }^{32} \mathrm{O}$ and ${ }^{1} \mathrm{Si}$ form a five-coordination intermediate by using the $3 \mathrm{~d}$ orbital of $\mathrm{Si}$. Afterwards, ${ }^{3} \mathrm{O}$ (NBO charge: -0.732 ) leaves from ${ }^{1} \mathrm{Si}$ (the ${ }^{3} \mathrm{O}-{ }^{1} \mathrm{Si}$ bond length increases from $1.710 \AA$ to $2.065 \AA$ ), and ${ }^{30} \mathrm{H}$ leaves from ${ }^{32} \mathrm{O}$ (the ${ }^{30} \mathrm{H}-{ }^{32} \mathrm{O}$ bond length increases from $0.985 \AA$ to $1.099 \AA$ ). This process crosses the barrier potential $\left(78.8 \mathrm{~kJ} \cdot \mathrm{mol}^{-1}\right)$, resulting in the transition state (TS- $\alpha-\mathrm{C}$ ). After that, ${ }^{32} \mathrm{O}$ keeps close to ${ }^{1} \mathrm{Si}$, (the ${ }^{32} \mathrm{O}-{ }^{1} \mathrm{Si}$ bond length increases from $1.803 \AA$ to $1.661 \AA$ ) resulting in an $\mathrm{Si}-\mathrm{O}$ bond. ${ }^{30} \mathrm{H}$ (NBO charge: 0.510 ) leaves from ${ }^{32} \mathrm{O}$ and keeps close to ${ }^{3} \mathrm{O}$, (the ${ }^{30} \mathrm{H}-{ }^{32} \mathrm{O}$ bond length increases from $1.099 \AA$ to1.814 $\AA$ and the ${ }^{30} \mathrm{H}-{ }^{3} \mathrm{O}$ bond length decreases from $1.368 \AA$ to $0.975 \AA$ ). Finally, the product $\mathrm{P}-\alpha-\mathrm{C}$ is obtained. Here, TS- $\alpha-\mathrm{C}$ was confirmed as first order saddle point by IRC analysis and the only imaginary frequency of transition is $-841.9 \mathrm{HZ}$.

Besides, the reaction between $\gamma$-EAMOS and $\mathrm{H}_{2} \mathrm{O}$ follows a similar pathway shown in Figure $\mathrm{S} 2$ and Tables S4-S6. 
3.2. The Highest Occupancy Orbit (HOMO) of Each Stationary Point of Reactions between $\alpha-, \gamma$-EAMOS and $\mathrm{H}_{2} \mathrm{O}$

The HOMO of the stationary points of the reactions between $\alpha-, \gamma$-EAMOS and $\mathrm{H}_{2} \mathrm{O}$ in Figures 2 and 3 were compared. In Re- $\alpha-\mathrm{C}\left(\mathrm{H}_{2} \mathrm{~N}\left(\mathrm{CH}_{2}\right)_{2} \mathrm{NHCH}_{2} \mathrm{Si}(\mathrm{O}-\mathrm{N}=\mathrm{CEtMe})_{3}\right)$, when $\mathrm{H}$ in the $\alpha$ position is replaced by an electronegative ethylenediamine group, ' $p$ ' electrons in $\mathrm{N}$ enter the $3 \mathrm{~d}$ orbital of $\mathrm{Si}$, resulting in $\mathrm{p}-\pi$ conjugation. Thus, the electronegativity of $\mathrm{Si}$ increases; it is easier to be attacked by nucleophiles. While electronegative $\mathrm{OH}$ in $\mathrm{H}_{2} \mathrm{O}$ comes close to $\mathrm{Si}$ to form a complex, the $\mathrm{Si}-\mathrm{O}$ bond will break easily and separate.

However, in Re- $\gamma-\mathrm{C}\left(\mathrm{H}_{2} \mathrm{~N}\left(\mathrm{CH}_{2}\right)_{2} \mathrm{NH}-\mathrm{CH}_{2} \mathrm{CH}_{2} \mathrm{CH}_{2} \mathrm{Si}(\mathrm{O}-\mathrm{N}=\mathrm{CEtMe})_{3}\right)$, the electron cloud of $\mathrm{N}$ will not conjugate with $\mathrm{Si}$ because the group lies far away from the $\mathrm{Si}$ atom. Thus, there is rare electron interaction on Si. As a result, the reaction between $\alpha$-EAMOS and $\mathrm{H}_{2} \mathrm{O}$ is easier than the reaction between $\gamma$-EAMOS and $\mathrm{H}_{2} \mathrm{O}$.
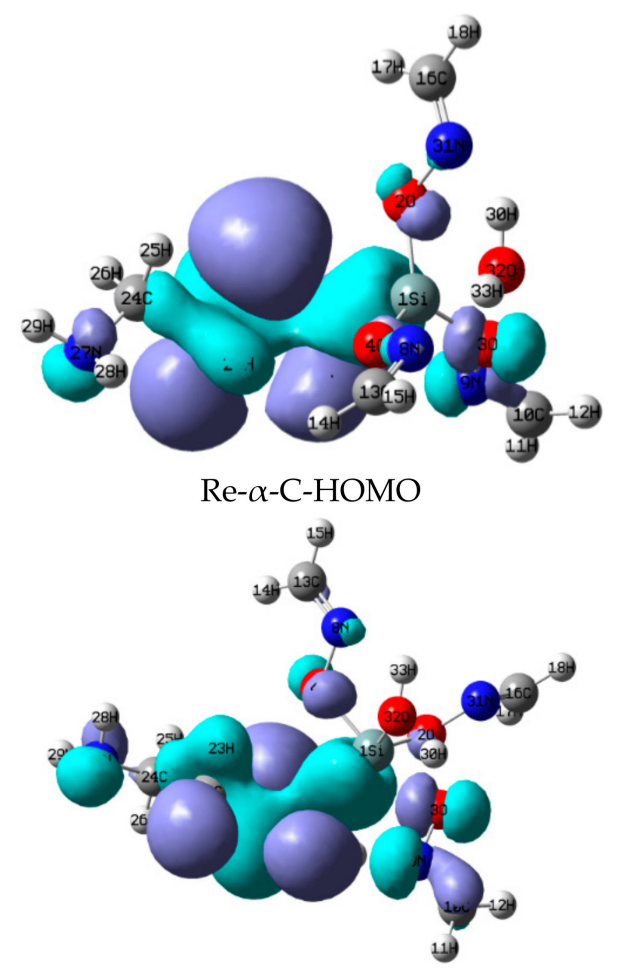

TS- $\alpha-\mathrm{C}-\mathrm{HOMO}$

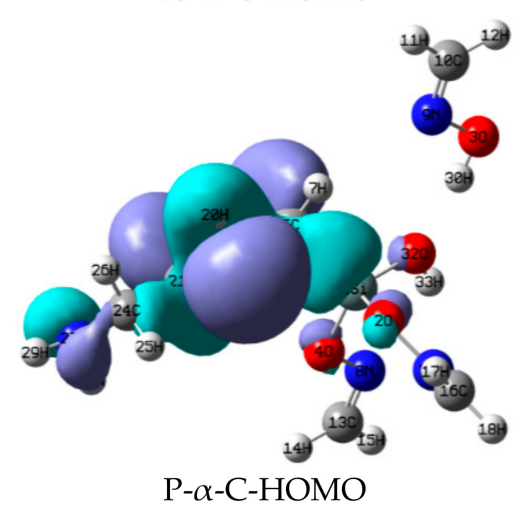

Figure 2. Highest occupied molecular orbital (HOMO) of stationary points of the reaction between $\alpha$-EAMOS and $\mathrm{H}_{2} \mathrm{O}$ at the B3LYP/ 6-311G ${ }^{* *}$ level. 

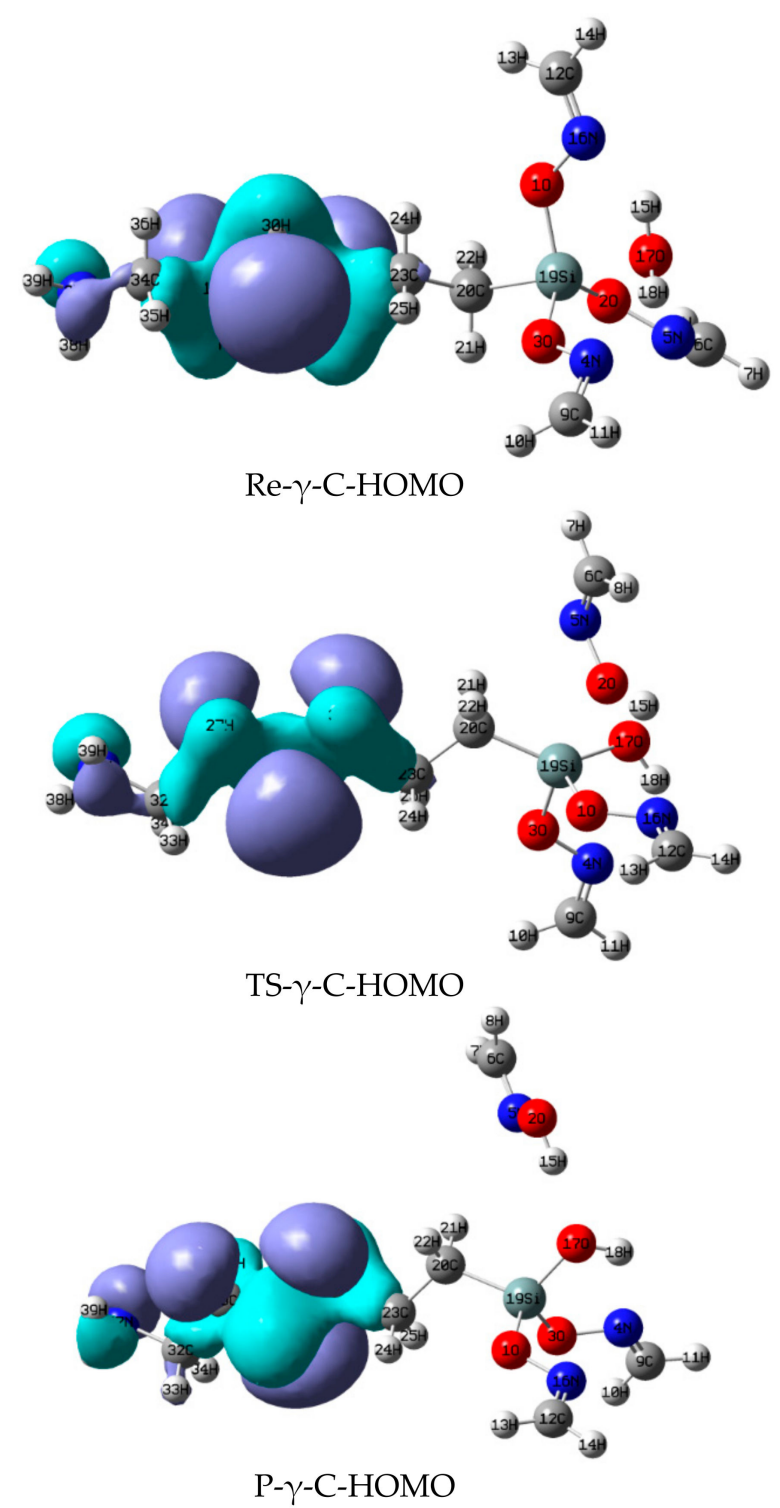

Figure 3. HOMO of stationary points of the reaction between $\gamma$-EAMOS and $\mathrm{H}_{2} \mathrm{O}$ at the B3LYP/6-311G** level.

\subsection{The Reaction between $\alpha$-EAMOS and $\mathrm{HO}-\mathrm{Si}_{(}\left(\mathrm{CH}_{3}\right)_{2}-\mathrm{OSiH}_{3}$}

IRC calculation (Figure 4, Tables S7-S9) showed that ${ }^{32} \mathrm{O}$ in $\mathrm{HO}-\mathrm{Si}\left(\mathrm{CH}_{3}\right)_{2}-\mathrm{OSiH}_{3}$ comes close to ${ }^{1} \mathrm{Si}$ (distance of ${ }^{1} \mathrm{Si}^{-32} \mathrm{O}$ from $4.127 \AA$ to $1.827 \AA$ ). Then, ${ }^{32} \mathrm{O}$ and ${ }^{1} \mathrm{Si}$ share a five-coordination bond by using the $3 \mathrm{~d}$ orbital of $\mathrm{Si}$. Afterwards, ${ }^{2} \mathrm{O}$ leaves from ${ }^{1} \mathrm{Si}$, (the ${ }^{1} \mathrm{Si}-{ }^{2} \mathrm{O}$ bond length increases from $1.684 \AA$ to $2.035 \AA$ ), and ${ }^{30} \mathrm{H}$ leaves from ${ }^{32} \mathrm{O}$, (the ${ }^{30} \mathrm{H}-{ }^{32} \mathrm{O}$ bond length increases from $0.969 \AA$ to $1.076 \AA$ ). This process crosses the barrier potential, $118.9 \mathrm{~kJ} \cdot \mathrm{mol}^{-1}$, resulting the transition state (TS-Si-OH). After that, ${ }^{32} \mathrm{O}$ keeps close to ${ }^{1} \mathrm{Si}$ (distance of ${ }^{32} \mathrm{O}-{ }^{1} \mathrm{Si}$ decreases from $1.827 \AA$ to $1.611 \AA$ ), resulting in a Si-O bond. ${ }^{30} \mathrm{H}$ leaves from ${ }^{32} \mathrm{O}$ and keeps close to ${ }^{2} \mathrm{O}$ (the ${ }^{30} \mathrm{H}-{ }^{32} \mathrm{O}$ bond length increases from $1.076 \AA$ to $3.004 \AA$ and the ${ }^{30} \mathrm{H}-{ }^{2} \mathrm{O}$ bond decreases from $1.387 \AA$ to $0.995 \AA$ ). Finally, the product $\mathrm{P}-\mathrm{Si}-\mathrm{OH}$ is obtained. Here, TS-Si-OH was confirmed as the first order saddle point by IRC analysis and the only imaginary frequency of transition is $-468.9 \mathrm{HZ}$. 


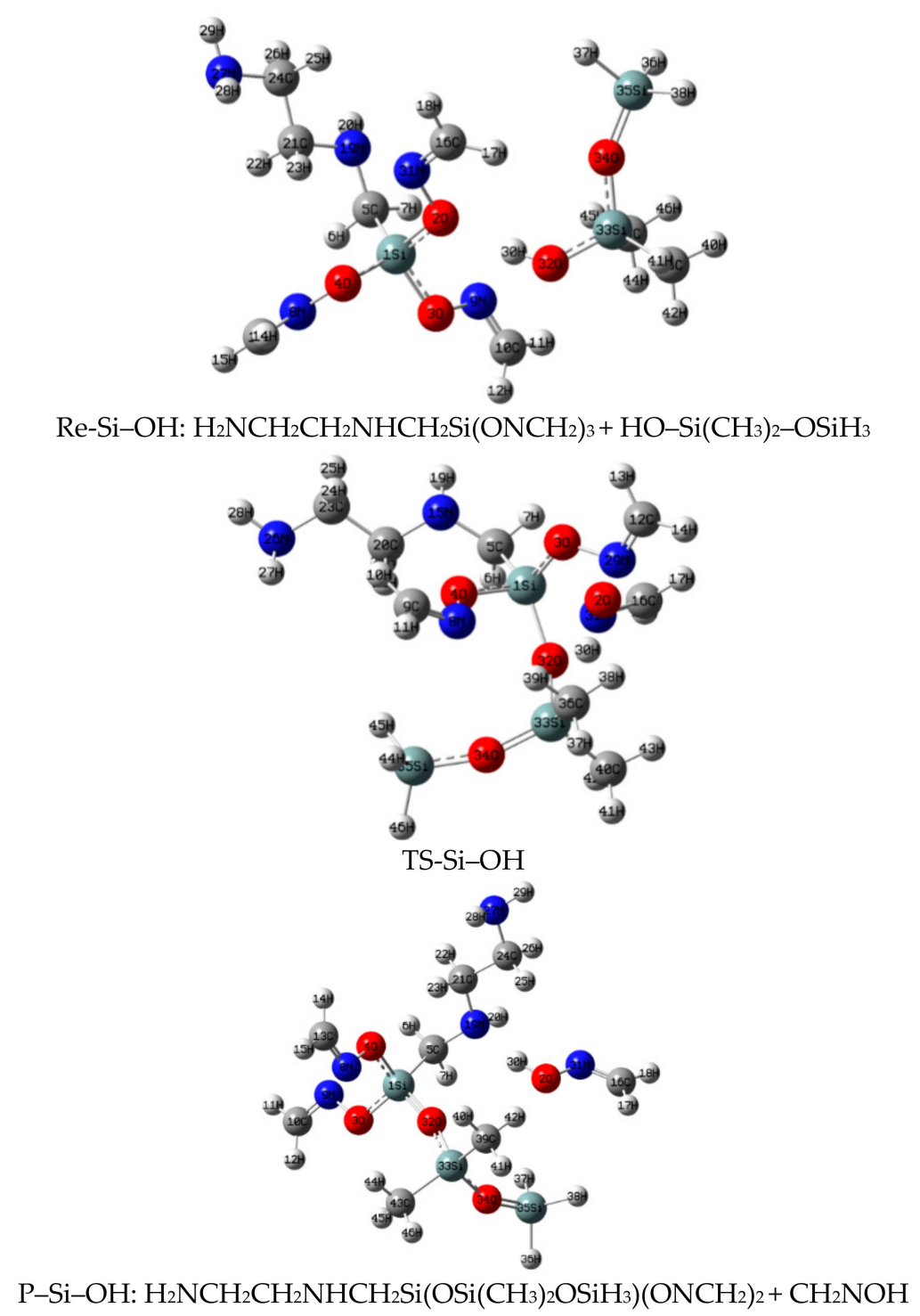

Figure 4. Geometries of stationary points of the reaction between $\alpha$-EAMOS and $\mathrm{HO}-\mathrm{Si}\left(\mathrm{CH}_{3}\right)_{2}-\mathrm{OSiH}_{3}$ at the B3LYP/6-311G** level.

\subsection{Thermodynamic and Kinetic Parameters}

The entropy changes from reactant to transition state were calculated using vibration frequency. They were based on the equilibrium geometries of the transition states (TS- $\alpha$, TS- $\gamma-\mathrm{C}$, TS-Si-OH) and the products $(\mathrm{P}-\alpha, \mathrm{P}-\gamma-\mathrm{C}, \mathrm{P}-\mathrm{Si}-\mathrm{OH})$. Then, the reaction rates were obtained by transition state theory, while entropy changes, enthalpy changes, Gibbs' free-energy changes, and the equilibrium constants were calculated by using statistical thermodynamic method. Kinetic analysis further proved the possibility and practicality of these reactions. For calculating rate constants, some insertion points were selected in both sides of the transition states along the steepest descent energy curve calculated by IRC. Then, the Hessian matrices of these points, reactants, products, and the transition states were calculated.

Rate constant: $\mathrm{k}(\mathrm{T})=\mathrm{g}\left(\mathrm{k}_{\mathrm{b}} \mathrm{T} / \mathrm{h}\right) \exp \left(\Delta \mathrm{S}^{\#} / \mathrm{R}-\Delta \mathrm{H}^{\#} / \mathrm{RT}\right)$

g: Wigner correction factor, $\mathrm{g}=1+\left(\mathrm{h} v^{\#} / \mathrm{k}_{\mathrm{b}} \mathrm{T}\right)^{2} / 24$;

$\mathrm{k}_{\mathrm{b}}$ : Boltzmann constant $\left(1.3806505(24) \times 10^{-23} \mathrm{~J} \cdot \mathrm{K}^{-1}\right)$;

$\mathrm{T}$ : thermodynamic temperature $(\mathrm{K})$; 
h: Planck constant $\left(6.6260693(11) \times 10^{-34} \mathrm{~J} \cdot \mathrm{s}\right)$;

R: molar gas constant $\left(8.31441 \pm 0.00026 \mathrm{~J} \cdot \mathrm{mol}^{-1} \cdot \mathrm{K}^{-1}\right)$;

$\mathrm{V}^{\#}$ : imaginary frequency of transition $\left(\mathrm{cm}^{3} \cdot \mathrm{mol}^{-1}\right)$;

$\Delta \mathrm{S}^{\#}$ : standard molar activation entropy $\left(\mathrm{J} \cdot \mathrm{mol}^{-1} \cdot \mathrm{K}^{-1}\right)$;

$\Delta \mathrm{H}^{\#}$ : standard molar activation enthalpy $\left(\mathrm{kJ} \cdot \mathrm{mol}^{-1}\right)$.

Equilibrium constant: $K(T)=\exp (-\Delta G \times 1000 /(8.314 T))$

$\Delta \mathrm{G}$ : Gibbs free energy $\left(\mathrm{kJ} \cdot \mathrm{mol}^{-1}\right)$.

As shown in the kinetic calculations in Tables 1 and 2, the rate constants will increase and the equilibrium constants will decrease gradually as the temperature increases. Interestingly, the reaction between $\alpha$-EAMOS and $\mathrm{H}_{2} \mathrm{O}$ has high rate constants and equilibrium constants. In detail, the reaction between $\alpha$-EAMOS and $\mathrm{H}_{2} \mathrm{O}$ has the highest rate constant which is three times that of $\gamma$-EAMOS and $\mathrm{H}_{2} \mathrm{O}$, and ten orders of magnitude higher than that of $\alpha$-EAMOS and $\mathrm{HO}-\mathrm{Si}\left(\mathrm{CH}_{3}\right)_{2}-\mathrm{OSiH}_{3}$ at $298 \mathrm{~K}$. This difference will decrease gradually as the temperature increases.

Table 1. Rate Constants k (T) calculated at the B3LYP/6-311G (d, p) level.

\begin{tabular}{cccc}
\hline \multicolumn{4}{c}{ Rate Constants k(T) $\left(\mathbf{s}^{-\mathbf{1}}\right)$} \\
\hline $\mathbf{T} / \mathbf{K}$ & $\alpha-\mathbf{C}$ & $\gamma-\mathbf{C}$ & Si-OH \\
\hline 298 & $3.23 \times 10^{-1}$ & $1.09 \times 10^{-1}$ & $4.80 \times 10^{-11}$ \\
400 & $1.48 \times 10^{3}$ & $3.66 \times 10^{2}$ & $8.81 \times 10^{-6}$ \\
500 & $2.10 \times 10^{5}$ & $4.12 \times 10^{4}$ & $1.04 \times 10^{-2}$ \\
600 & $5.79 \times 10^{6}$ & $9.45 \times 10^{5}$ & $1.16 \times 10^{0}$ \\
700 & $6.29 \times 10^{7}$ & $8.76 \times 10^{6}$ & $3.35 \times 10^{1}$ \\
800 & $3.79 \times 10^{8}$ & $4.61 \times 10^{7}$ & $4.19 \times 10^{2}$ \\
900 & $1.54 \times 10^{9}$ & $1.66 \times 10^{8}$ & $2.99 \times 10^{3}$ \\
1000 & $4.78 \times 10^{9}$ & $4.63 \times 10^{8}$ & $1.45 \times 10^{4}$ \\
1100 & $1.21 \times 10^{10}$ & $1.06 \times 10^{9}$ & $5.26 \times 10^{4}$ \\
1200 & $2.63 \times 10^{10}$ & $2.12 \times 10^{9}$ & $1.55 \times 10^{5}$ \\
1300 & $5.09 \times 10^{10}$ & $3.78 \times 10^{9}$ & $3.86 \times 10^{5}$ \\
1400 & $8.98 \times 10^{10}$ & $6.19 \times 10^{9}$ & $8.45 \times 10^{5}$ \\
1500 & $1.47 \times 10^{11}$ & $9.46 \times 10^{9}$ & $1.67 \times 10^{6}$ \\
\hline
\end{tabular}

Table 2. Equilibrium Constants K (T) calculated at the B3LYP/6-311G (d, p) level.

\begin{tabular}{cccc}
\hline \multicolumn{4}{c}{ Equilibrium Constants K(T) } \\
\hline T/K & $\alpha$-C & $\gamma$-C & Si-OH \\
\hline 298 & $1.04 \times 10^{14}$ & $5.79 \times 10^{13}$ & $9.28 \times 10^{11}$ \\
400 & $1.71 \times 10^{11}$ & $1.06 \times 10^{11}$ & $4.56 \times 10^{8}$ \\
500 & $4.12 \times 10^{9}$ & $2.73 \times 10^{9}$ & $5.10 \times 10^{6}$ \\
600 & $3.48 \times 10^{8}$ & $2.41 \times 10^{8}$ & $2.49 \times 10^{5}$ \\
700 & $6.01 \times 10^{7}$ & $4.26 \times 10^{7}$ & $2.84 \times 10^{4}$ \\
800 & $1.61 \times 10^{7}$ & $1.17 \times 10^{7}$ & $5.50 \times 10^{3}$ \\
900 & $5.80 \times 10^{6}$ & $4.26 \times 10^{6}$ & $1.53 \times 10^{3}$ \\
1000 & $2.56 \times 10^{6}$ & $1.91 \times 10^{6}$ & $5.45 \times 10^{2}$ \\
1100 & $1.32 \times 10^{6}$ & $9.87 \times 10^{5}$ & $2.34 \times 10^{2}$ \\
1200 & $7.55 \times 10^{5}$ & $5.71 \times 10^{5}$ & $1.15 \times 10^{2}$ \\
1300 & $4.71 \times 10^{5}$ & $3.59 \times 10^{5}$ & $6.34 \times 10^{1}$ \\
1400 & $3.15 \times 10^{5}$ & $2.41 \times 10^{5}$ & $3.79 \times 10^{1}$ \\
1500 & $2.22 \times 10^{5}$ & $1.71 \times 10^{5}$ & $2.43 \times 10^{1}$ \\
\hline
\end{tabular}

As the thermodynamic calculations in Table S10 show, the reaction between $\alpha$-EAMOS and $\mathrm{H}_{2} \mathrm{O}$ is entropy-increasing, exothermic, and spontaneous. The reaction between $\alpha$-EAMOS and 
$\mathrm{HO}-\mathrm{Si}\left(\mathrm{CH}_{3}\right)_{2}-\mathrm{OSiH}_{3}$ is exothermic, spontaneous, but entropy-decreasing. This is due to the polyreaction of two reactants from disorder to order. Besides, the reactions between $\alpha$-EAMOS and $\mathrm{H}_{2} \mathrm{O}$ exhibit similar aviation energy $\left(78.8 \mathrm{~kJ} \cdot \mathrm{mol}^{-1}\right.$, Tables $\mathrm{S} 2$ and S5), while that of $\alpha$-EAMOS and $\mathrm{HO}-\mathrm{Si}\left(\mathrm{CH}_{3}\right)_{2}-\mathrm{OSiH}_{3}\left(118.9 \mathrm{~kJ} \cdot \mathrm{mol}^{-1}\right.$, Table S8) is higher.

In conclusion, $\alpha$-functionalized silanes have a fast hydrolysis rate. Using $\alpha$-functionalized ketoxime silanes as effective autocatalytic crosslinkers in RTV silicone rubber by decreasing the tack-free time and improving thermal stability (Figure S3) [15] or mechanical properties has been reported $[16,21,22]$. Besides, $\alpha$-functionalized silanes are easier to react with $\mathrm{H}_{2} \mathrm{O}$ on the surface of silicone rubber but difficult to react with HO-PDMS (silicone rubber gum) in the vulcanizing system. It proved that the corresponding silicone rubber is difficult to deep vulcanize at room temperature.

\section{Conclusions}

According to DFT calculations, the amine group on $\alpha$-EAMOS is only one $\mathrm{C}$ atom away from $\mathrm{Si}$, and the lone pair of electrons on the amine can be conjugated into the $3 \mathrm{~d}$ orbital of $\mathrm{Si}$, thus increasing the electronegativity of Si. Then, the hydrolyzable group on $\mathrm{Si}$ was attacked easily by $\mathrm{H}_{2} \mathrm{O}$. But, there is no conjugation effect in $\gamma$-EAMOS, whose hydrolysis rate was lower than that of $\alpha$-EAMOS. Interestingly, it proved that $\alpha$-amino substituted alkoxy silanes could be used as efficient crosslinkers in RTV silicone rubber.

Besides, the reaction between $\alpha$-EAMOS and $\mathrm{H}_{2} \mathrm{O}$ had a faster reaction rate, lower activation energy, and higher reaction trend than those of the reaction between $\alpha$-EAMOS and $\mathrm{HO}-\mathrm{Si}\left(\mathrm{CH}_{3}\right)_{2}-\mathrm{OSiH}_{3}$. So, $\alpha$-functionalized ketoxime silanes could react with $\mathrm{H}_{2} \mathrm{O}$ quickly on the surface of silicone rubber but they are difficult to react with HO-PDMS. Then, there is rare cross-linking effect inside. As a result, the deep vulcanization of the corresponding silicone rubber is difficult.

Here, DFT calculations were explanative and markedly consistent with our experimental results. Not only is this study important for basic research, it may also facilitate an increase in the use of $\alpha$-functionalized ketoxime silanes to improve the properties of RTV silicone rubber in the silicon industry.

Supplementary Materials: The following are available online at http:/ /www.mdpi.com/1996-1944/11/9/1526/ s1, Table S1: B3LYP / 6-311 $\mathrm{G}^{* *}$ structural parameters of the reaction between $\alpha$-EAMOS and $\mathrm{H}_{2} \mathrm{O}$ [bond length: $\AA$; bond angle: $\left({ }^{\circ}\right)$; dihedral: $\left({ }^{\circ}\right)$ ], Table S2: Absolute energies, zero-point energies and relative energies of reactants, transition states and products of the reaction between $\alpha$-EAMOS and $\mathrm{H}_{2} \mathrm{O}$ calculated at B3LYP / 6-311G $\mathrm{G}^{* *}$ level, Table S3: The natural atomic charges of the reaction between $\alpha$-EAMOS and $\mathrm{H}_{2} \mathrm{O}$ calculated at B3LYP / 6-311G** level, Table S4: B3LYP $/ 6-311 \mathrm{G}^{* *}$ structural parameters of the reaction between $\gamma$-EAMOS and $\mathrm{H}_{2} \mathrm{O}$ [bond length: $\AA$; bond angle: $\left(^{\circ}\right)$; dihedral: $\left(^{\circ}\right)$ ], Table S5: Absolute energies, zero-point energies and relative energies of reactants, transition states and products of the reaction between $\gamma$-EAMOS and $\mathrm{H}_{2} \mathrm{O}$, calculated at B3LYP/6-311G** level, Table S6: The natural atomic charges of the reaction between $\gamma$-EAMOS and $\mathrm{H}_{2} \mathrm{O}$, calculated at B3LYP/6-311G** level, Table S7: B3LYP/6-311G** structural parameters of the reaction between $\alpha$-EAMOS and HO-Si(CH3)2-OSiH3 [bond length: $\AA$; bond angle: $\left({ }^{\circ}\right)$; dihedral: $\left({ }^{\circ}\right)$ ], Table S8: Absolute energies, zero-point energies and relative energies of reactants, transition states and products of the reaction between $\alpha$-EAMOS and $\mathrm{HO}-\mathrm{Si}\left(\mathrm{CH}_{3}\right)_{2}-\mathrm{OSiH}_{3}$, calculated at B3LYP/6-311G $\mathrm{G}^{* *}$ level, Table S9: The natural atomic charges of the reaction between $\alpha$-EAMOS and $\mathrm{HO}-\mathrm{Si}(\mathrm{CH} 3) 2-\mathrm{OSiH} 3$, calculated at B3LYP/6-311G $\mathrm{G}^{* *}$ level, Table S10: Entropy changes, enthalpy changes and Gibbs free energies calculated at B3LYP/6-311G $(d, p)$ level, Figure S1: Total energy along IRC of reaction between $\alpha$-EAMOS and H2O, Figure S2:B3LYP $/ 6-311 \mathrm{G}^{* *}$ geometries of stationary points of the reaction between $\gamma$-EAMOS and H2O, Figure S3: TGA curves of the elastomer including $\alpha$-silanes or MOS and PDMS ( $\alpha$-silanes: PDMS $=1: 10)$.

Author Contributions: Y.B. conceived and designed the experiments; H.X. and Y.G. performed the experiments; H.X. and Z.L. analyzed the data; Y.B. contributed reagents/materials/analysis tools; and H.X. and Y.B. wrote the paper.

Funding: This work was financially supported by National Natural Science Foundation of China (No. 20874057).

Acknowledgments: The authors wish to express their appreciations to the Structural Component Testing Center, Shandong University.

Conflicts of Interest: The authors declare no conflict of interest. 


\section{References}

1. Baur, S.I.; Easteal, A.J. Improved photoprotection of wood by chemical modification with silanes: NMR and ESR studies. Polym. Adv. Technol. 2013, 24, 97-103. [CrossRef]

2. Keppeler, M.; Holzbock, J.; Rgen, U.; Akbarzadeh, J.; Peterlik, H.; Uuml, H.; Sing, N. Nucleophilic substitution on silica surfaces: Comparison of the reactivity of $\alpha$-versus $\gamma$-chlorosubstituted silanes in the reaction with sodium azide. J. Ceram. Soc. Jpn. 2015, 123, 764-769. [CrossRef]

3. Ni, Y.; Jiang, J.X.; Wu, J.R.; Wu, L.B. A study of silicone rubber of condense type adhesion to metal. J. Hangzhou Teach. Coll. 2005, 2, 118-120.

4. Dong, F.; Diao, S.; Ma, D.; Zhang, S.; Feng, S. Preparation and characterization of 3-chloropropyl polysiloxane-based heat-curable silicone rubber using polyamidoamine dendrimers as cross-linkers. React. Funct. Polym. 2015, 96, 14-20. [CrossRef]

5. Bauer, A.; Kammel, T.; Pachaly, B.; Schafer, O.; Schindler, W.; Stanjek, V.; Weis, J. Organosilicon Chemistry V-From Molecules to Materials; Auner, N., Weis, J., Eds.; Wiley-VCH: Weinheim, Germany, 2003; pp. 527-535.

6. Stanjek, V.; Weidner, R. Silicon for the Chemical and Solar Industry X; Øye, H.A., Brekken, H., Nygaard, L., Eds.; Department of Materials Science and Engineering, Norwegian University of Science and Technology: Trondheim, Norway, 2010; pp. 1-12.

7. GENIOSIL-Organofunktionelle Silane von WACKER. Brochure of the Wacker Company: Munich, Germany, 2011. Available online: http://www.wacker.com/cms/media/publications/download/6085_EN.pdf (accessed on 20 February 2011).

8. Zhou, Q.; Cao, Y.; Yang, C.; Xia, X.; Yang, S. $\alpha$-Functionalized silane coupling agents. Chem. Eng. Jiangsu 1984, 11, 25-30.

9. Zhao, Q. Synthesis and Applications of $\alpha$-Aminohydrocarbylsubstituted Ketoximosilane in RTV Silicone Rubber. Master's Thesis, Shandong University, Jinan, China, June 2015.

10. Berkefeld, A.; Guerra, C.F.; Bertermann, R.; Troegel, D.; Daiß, J.O.; Stohrer, J.; Bickelhaupt, F.M.; Tacke, R. Silicon $\alpha$-Effect: A Systematic Experimental and Computational Study of the Hydrolysis of $\mathrm{C} \alpha$ - and $\mathrm{C} \gamma$-Functionalized Alkoxytriorganylsilanes of the Formula Type $\mathrm{ROSiMe}_{2}\left(\mathrm{CH}_{2}\right)_{\mathrm{n}} \mathrm{X}(\mathrm{R}=\mathrm{Me}, \mathrm{Et} ; \mathrm{n}=1,3 ; \mathrm{X}=$ Functional Group). Organometallics 2014, 33, 2721-2737. [CrossRef]

11. Peng, Z.; Wang, Y.; Wu, Q.; Wang, H. Study on water-based RTV silicone rubber having self-catalytic crosslinker. Chin. Elastom. 2005, 2, 27-32.

12. Brahne, C.; Steinjek, V.; Weidner, R. The Improvement of Stability of Aminemethylaloxylsilanes with Hyperreactivity. Patent No. CN 101072782, 14 November 2007.

13. Che, G.; Zhai, T.; Luo, D.; Xiong, T.; Wang, Y. $\alpha$-Silane Coupling Agents and their Applications. Patent No. CN 105111231 A, 9 September 2015.

14. Bei, Y.; Zhao, Q.; Feng, S.; Zhu, Q. The Synthesis Method of one Kind of $\alpha$-Amine ketoximesilanes. Patent No. CN 104650128 A, 13 March 2015.

15. $\mathrm{Xu}, \mathrm{H}$. Synthesis, Hydrolysis Activity of $\alpha$-Silanes and Application in Room Temperature Vulcanized Silicone Rubber. Master's Thesis, Shandong University, Jinan, China, June 2017.

16. Zhao, Q.; Liu, Q.; Xu, H.; Bei, Y. Preparation and characterization of room temperature vulcanized silicone rubber using $\alpha$-amine ketoximesilanes as auto-catalyzed cross-linkers. RSC Adv. 2016, 6, 38447-38453. [CrossRef]

17. Feng, S.; Zhang, J.; Li, M.; Zhu, Q. Study on water-based RTV silicone rubber having self-catalytic crosslinker. In Organic Silicon Polymer and Application; Chemical Industry Press: Jinan, China, 2004; pp. 116-151.

18. Ramakrishnan, I.; Nesakumar, E.J. Architectural Unit Possessing Rapid Deep-Section Cure Silicone Rubber Component. Patent No. WO US7993754, 8 September 2011.

19. Teng, A.; Li, W.; Qin, J.; Wu, V.; Zhang, L. Fast Curing Condensation RTV Silicone Rubber in Bonding Application. Patent No. WO 2016/030185 A1, 3 March 2016.

20. Frisch, M.J.; Trucks, G.W.; Schlegel, H.B.; Scuseria, G.E.; Robb, M.A.; Cheeseman, J.R.; Montgomery, J.A.; Vreven, T.; Kudin, K.N.; Burant, J.C.; et al. Gaussian 03; Gaussian, Inc.: Pittsburgh, PA, USA, 2003. 
21. Bei, Y.; Xu, H.; Zhu, Q.; Feng, S. The Preparation Method of Auto-Catalyzed Room Temperature Vulcanized Silicone Rubber. Patent No. CN 105111747 A, 12 October 2015.

22. Xu, H.; Liu, Z.; Liu, Q.; Bei, Y.; Zhu, Q. Impacts of Different Functional Groups on the Kinetic Rates of $\alpha$-Amine Ketoximesilanes Hydrolysis in the Preparation of Room Temperature Vulcanized Silicone Rubber. Materials 2018, 11, 790. [CrossRef] [PubMed] 